\title{
Biology and Sources of Inoculum of Geotrichum candidum Causing Sour Rot of Peach and Nectarine Fruit in California
}

\author{
Mohammad A. Yaghmour and Richard M. Bostock, Department of Plant Pathology, University of California, Davis 95616; and \\ David P. Morgan and Themis J. Michailides, Department of Plant Pathology, University of California, Kearney Agricultural Center, \\ Parlier 93648
}

\begin{abstract}
Yaghmour, M. A., Bostock, R. M., Morgan, D. P., and Michailides, T. J. 2012. Biology and sources of inoculum of Geotrichum candidum causing sour rot of peach and nectarine fruit in California. Plant Dis. 96:204-210.

Geotrichum candidum causes sour rot of fresh-market stone fruit such as peach and nectarine. Since 2001, the incidence of sour rot has increased in California, a semi-arid production area, which is considered atypical for the occurrence of the disease. In this study, sour rot developed at significantly higher incidence on wounded fruit compared with unwounded fruit, and disease severity increased as fruit matured. In packinghouse surveys, sour rot was found on up to $4 \%$ of non-fungicide-treated peach and nectarine fruit. In laboratory assays, sour rot developed when fruit were inoculated with a minimum of 20 conidia per inoculation site. Inoculum of $G$. candidum could be detected in California orchard soils at depths of up to $10 \mathrm{~cm}$. The amount of inoculum in the soil was positively correlated with that on leaf and fruit

candidum was detected at different areas of packing lines in seven packinghouses. There were significant differences among the packinghouses evaluated, and these differences could be attributed, in part, to different sanitation practices used. Nitidulid beetles and fruit flies were found to play a role in disease transmission. These insects acquired sour rot inoculum in the orchard, and $25 \%$ of nitidulid beetles and $26 \%$ of fruit flies collected were positive for the pathogen. Spore survival in the soil over a 12-month period decreased significantly when soil depth increased from 10 to $20 \mathrm{~cm}$. This study identified sources of inoculum of $G$. candidum in orchards and packinghouses, and provides information to guide development of disease management programs under the semi-arid conditions of California.
\end{abstract} surfaces of trees growing at a specific site. Moreover, inoculum of $G$.
Postharvest decay is a significant problem that complicates storage and shipment of fresh produce, resulting in serious economic losses. It is estimated that $25 \%$ of perishable crops are lost in the postharvest chain. In stone fruit from orchards in semi-arid regions, fruit rots caused by the postharvest pathogens Monilinia fructicola, Rhizopus stolonifer, and Botrytis cinerea are prevalent (13). Fruit rots caused by the fungal pathogens Gloeosporium gloeosporioides and Geotrichum candidum are more prevalent in humid regions (13). G. candidum causes sour rot of processing and fresh-market fruit such as peach and nectarine $(5,19,31)$, tomato $(6,13)$, and cantaloupe (30). Occasionally, sour rot-like decays may also be caused by other yeasts and possibly other fungi that have not been well characterized $(19,31)$. The incidence of sour rot decay has increased since 2001 in California, which is considered a semi-arid production area and, thus, is thought to have an atypical and unfavorable climate for this disease.

Sour rot of peach and nectarine is mainly associated with injured or bruised fruit and fruit with split pits (1). Furthermore, the disease mainly occurs on ripe fruit but may also occur on severely injured immature fruit. Symptoms include a brown, watery, soft decay with a thin layer of white mycelial growth on the fruit surface (31). The decay may reach the pit and consume the entire fruit (5). Rotted fruit have a characteristic odor, ranging from yeasty to vinegary; juice may stream from the lesion, causing the skin to disintegrate and form furrows (19) (Fig. 1). Postharvest handling and marketing practices that minimize fruit injuries include sanita-

Corresponding author: T. J. Michailides, E-mail: themis@uckac.edu

* The $\boldsymbol{e}$-Xtra logo stands for "electronic extra" and indicates that Figure 1 appears in color in the online edition.

Accepted for publication 3 August 2011.

http://dx.doi.org/10.1094/PDIS-05-11-0391

() 2012 The American Phytopathological Society tion practices during fruit packing and implementation of proper cold-temperature $\left(0\right.$ to $\left.1.7^{\circ} \mathrm{C}\right)$ storage of harvested fruit. These practices can reduce the disease incidence to very low levels $(2,13,31)$. Occasionally, fruit decay can also occur during transportation if temperatures rise above $2^{\circ} \mathrm{C}(31)$. In general, the incidence of sour rot developing during shipping is less than $3 \%$ on peach and nectarine fruit (1). The increase in the incidence of sour rot in recent years in California appears to be associated with changes in post-harvest temperature management such as preconditioning, relaxation of sanitation requirements, and postharvest handling practices that lead to fruit injuries (2).

Preconditioning (preripening) of peach and nectarine is widely used by packinghouses and farmers in California to improve the quality of fruit shipped to distant markets $(2,12)$. Preconditioning of fruit reduces internal breakdown, a physiological disorder that results from chilling injury (12). Preconditioning typically involves subjecting the fruit to a 48 -h storage period at $20^{\circ} \mathrm{C}$ and high relative humidity $(\mathrm{RH} ;>95 \%)$ prior to cold-temperature storage at $0^{\circ} \mathrm{C}$ (12). In general, senescent and ripened fruit are very susceptible to most fruit decay pathogens, and laboratory treatments that block wound healing and lead to fruit senescence increase the incidence of fruit decay (2). Preconditioned peach and nectarine fruit are also closer to senescence and, thus, are more susceptible to fungal decays, including those caused by G. candidum (1).

Dispersal of sour rot inoculum appears to be mainly by soil dust and rain splashing. Insects also have been shown to transmit propagules of the pathogen. Transmission of G. candidum in tomato and of some other postharvest decay pathogens of peach and nectarine is associated with vinegar flies (Drosophila melanogaster) and nitidulid beetles (Carpophilus spp.) (7,8,23,29). Thus, insects can play a role in sour rot epidemiology and the disease cycle but their importance for stone fruit has not been established.

The objective of this research was to understand the disease cycle of sour rot of peach and nectarine in major stone-fruit-producing areas in California. Studies were conducted to identify inoculum sources, assess population densities of $G$. candidum in orchards and packinghouses, and evaluate the contribution of in- 
sects in transmission of $G$. candidum. This information will be needed for the development and implementation of effective control measures against sour rot of stone fruit.

\section{Materials and Methods}

G. candidum isolate and inoculum preparation. The isolate of G. candidum (06-47) used in this study for inoculation of fruit originated from soil in a commercial stone fruit orchard with a history of sour rot. G. candidum (06-47) was isolated using the method of Butler and Eckert (9) in summer 2004 as part of a preliminary study of the occurrence of the pathogen in peach and nectarine orchards. This isolate was maintained as a stock culture as a conidial (arthrospores) suspension in water at $4^{\circ} \mathrm{C}$. For preparation of inoculum, conidia were drawn from this culture with a sterile loop and plated on potato dextrose agar (PDA; Microtech Scientific, Orange, CA) containing novobiocin (Sigma-Aldrich, St. Louis) $100 \mathrm{mg} / \mathrm{liter}$, as described by Butler and Eckert (9) but modified with the addition of fludioxonil (Syngenta, Greensboro, $\mathrm{NC}$ ) at $1 \mathrm{mg} / \mathrm{liter}$ (PDANF). Conidial inoculum was then prepared from the fungal colonies emerging on these plates after $48 \mathrm{~h}$.

Sources of inoculum in the field and on harvest equipment. Soil as well as peach and nectarine leaves and fruit were sampled from 43 orchards in three counties in California from 2006 to 2008. A soil core sampler was used to obtain three soil samples in each orchard to a depth of up to $2.5 \mathrm{~cm}$. Soil samples were allowed to air dry for 5 days. Aliquots of $10 \mathrm{~g}$ dry weight of soil were transferred to 50-ml plastic tubes into which $25 \mathrm{ml}$ of water were added (BD Bioscience, Franklin Lakes, NJ). The tubes were shaken overnight on a horizontal shaker at $180 \mathrm{rpm}$. Soil suspensions were filtered through a double layer of cheesecloth and an aliquot (50 $\mu \mathrm{l})$ of the filtered suspension was applied to each of three replicate plates containing PDANF media using an Eddy Jet spiral plater (Neutec Group Inc., New York). The "E" mode, which spreads 50 $\mu \mathrm{l}$ onto $9-\mathrm{cm}$ plates, was selected. Plates were incubated at 23 to $25^{\circ} \mathrm{C}$ for $48 \mathrm{~h}$. CFU were enumerated by visual inspection following the manufacturer's instructions and calculated as CFU/g of soil dry weight.

To determine propagules of G. candidum on fruit and leaves, 30 fruit and 25 leaves were collected from 43 orchards each year from 2006 to 2008 and washed with 100 and $25 \mathrm{ml}$, respectively, of sterile distilled water containing $0.005 \%$ Tween 20 (SigmaAldrich). An aliquot $(0.2 \mathrm{ml})$ of each wash solution was spread onto each of three replicate PDANF plates using a microbiological spreader and the plates were incubated at $25^{\circ} \mathrm{C}$ for $48 \mathrm{~h}$.

To evaluate for a possible relationship between soil population and percentage of organic matter in the soil, a composite soil sample of representative fields with different propagule levels of $G$. candidum and soils from fields that did not yield any G. candidum were submitted to the University of California Davis Analytical Laboratory for analysis of organic matter content (24).

To compare soil populations of $G$. candidum at different soil depths, samples were collected from three fields in 2007 and 2008. The soil type at these locations was Hanford fine sandy loam. Triplicate samples of soil ( $500 \mathrm{~g} / \mathrm{sample})$ were collected at depths of $2.5,5$, and $10 \mathrm{~cm}$ using a soil core sampler $(2.5 \mathrm{~cm}$ in diameter $)$ and population levels of $\mathrm{G}$. candidum were determined as described previously.

To determine whether propagules of $G$. candidum exist on harvest equipment, five different harvest bins and boxes ("totes") from two packinghouses were sampled weekly for 11 weeks. The presence and population size of $G$. candidum were determined with Rodac plates (Microtech Scientific) containing PDANF medium. These plates were filled with the medium and inoculated by gently appressing them to the surfaces of the harvest equipment. The plates were then covered and incubated for $48 \mathrm{~h}$ at $23 \pm 2{ }^{\circ} \mathrm{C}$, and G. candidum colonies were enumerated as described previously to determine the population density.

Sources of inocula in the packinghouses and ripening rooms. Seven packinghouses were surveyed for the presence of $G$. candidum at four locations of the packing line: belt at the unloading site (area 1), brushes of the fungicide treatment bed (area 2), belt after the fungicide treatment bed (area 3 ), and belt at the final pack site (area 4). Rodac plates containing PDANF medium were used to sample surfaces of the different areas of the packing line that come into direct contact with fruit. Packing lines were sampled four times in each of four packinghouses in 2006 and seven times in each of seven packinghouses in 2007 and 2008. Three plates were used to sample each area at each sampling site. Numbers of G. candidum colonies were recorded after incubating the plates for $48 \mathrm{~h}$ at $25^{\circ} \mathrm{C}$ and the three readings per area were averaged. To sample the ripening room, an Andersen spore trap (Andersen Instruments Inc., Smyrna, GA) containing six plates of PDANF medium was operated for $2 \mathrm{~h}$ in the middle of the room, using an intake velocity setting of $2.3 \mathrm{~m}^{3} / \mathrm{h}$. The plates were incubated as described earlier. This experiment was performed twice in one packinghouse in 2009.

Incidence of sour rot in commercial orchards. Harvest-maturity nectarine fruit of 'Honey Blaze', 'Rubi Diamond', and 'Summer Fire' with similar skin color were handpicked from commer-

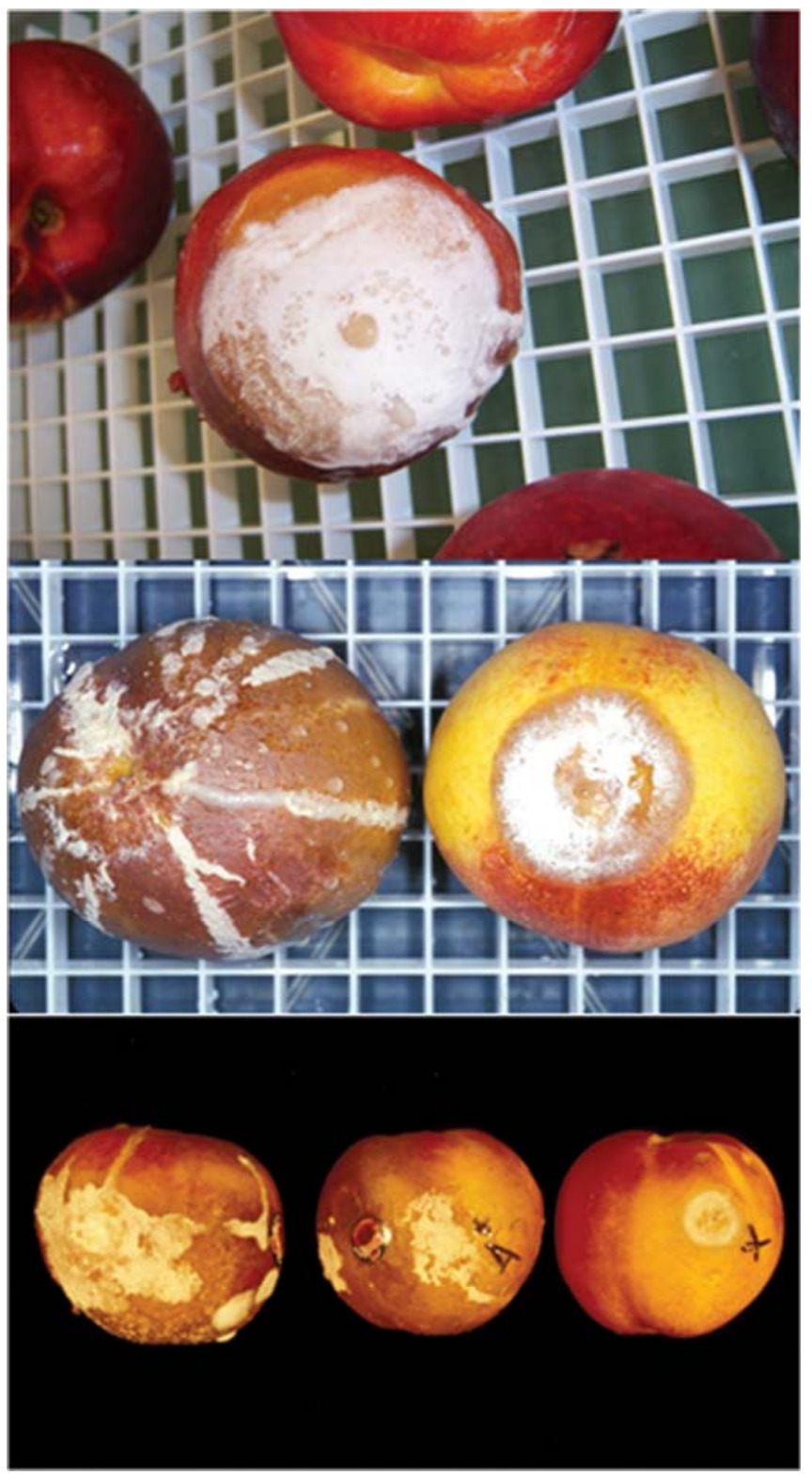

Fig. 1. Symptoms of sour rot caused by Geotrichum candidum on inoculated nectarine fruit in the laboratory and on commercial fruit. Watery, soft decay with a thin layer of white mycelial growth on the fruit surface. Decay may reach the pit and consume the entire fruit. Rotted fruit have a characteristic yeasty to vinegary odor; juice may stream from the lesion, causing the skin to disintegrate and form furrows. 
cial orchards with a history of sour rot in 2004 and 2005. Three more nectarine cultivars-'Royal Lady', 'August Fire', and 'Summer Fire'-were sampled from another set of orchards in 2006 and 2007. The two sets of orchards are managed by two growers who operate their own packinghouses. For each orchard, 10 boxes of 48 fruit each were harvested by placing 24 fruit each in plastic liners, with two liners used per box. The boxes were incubated at $20^{\circ} \mathrm{C}$ and $>90 \%$ RH for 5 days. After incubation, fruit were examined macroscopically and microscopically as needed. The percentage of fruit with sour rot symptoms was recorded. Isolations were made from every fruit with sour rot symptoms to confirm the presence of G. candidum and to obtain additional isolates from the field for further studies.

Survival of $G$. candidum in soil at two soil depths. To determine the survival of conidia of G. candidum in orchard soils, 30 market-mature nectarine ('Summer Fire') were surface sterilized by dipping in a solution containing $0.1 \% \mathrm{NaOCl}, 1.6 \%$ ethyl alcohol, and $0.005 \%$ Tween 20 for $4 \mathrm{~min}$. Each fruit was wound inoculated with $20 \mu \mathrm{l}$ of $10^{6}$ conidia/ml and incubated until all fruit were completely decayed by the fungus and covered by white sporulation. After removing the pits, fruit were homogenized with 3 liters of distilled water and mixed by hand with $25 \mathrm{~kg}$ of soil (Hanford fine loam). The mixture was placed into 12 wire baskets (21). The baskets (two baskets for each of three replicates) were buried 10 or $20 \mathrm{~cm}$ deep in a peach orchard at the University of California Kearney Agricultural Center in Parlier, where standard commercial cultural practices were performed, with the exception of fungicide applications. Soil cores were collected using a soil core sampler twice a month for 12 months. Soil samples were processed following storage at $4^{\circ} \mathrm{C}$ for up to 8 weeks. Soil was allowed to air dry to a constant weight at 23 to $25^{\circ} \mathrm{C}$ ( 2 to 3 days), and $5 \mathrm{~g}$ of soil were then mixed with $25 \mathrm{ml}$ of sterile deionized water. The soil suspension was filtered through cheesecloth and was spiral plated onto PDANF media using a spiral plater (Eddy Jet; Neutec Group Inc.). The plates were incubated for $48 \mathrm{~h}$ at $25^{\circ} \mathrm{C}$, and soil populations of $G$. candidum were calculated as described previously.

Effect of fruit maturity, wounding, and inoculum concentration on disease development. Nectarine fruit ('May Glo') at different maturity stages were obtained from orchards at the Kearney Agricultural Center. Increasing maturity correlates with decreasing firmness as measured with a pressure tester (model FT327; Alfonsine, Italy). The four maturity stages selected were (i) immature green fruit (6.8 to $9.5 \mathrm{~kg}$ of resistance), (ii) mature fruit (5.0 to $5.4 \mathrm{~kg}$ of resistance), (iii) market mature fruit $(2.7$ to $3.6 \mathrm{~kg}$ of resistance), and (iv) soft fruit ( 0.9 to $1.4 \mathrm{~kg}$ of resistance). Fruit were stored for up to 3 weeks at 1 to $2^{\circ} \mathrm{C}$ until use. Fruit were surface sterilized as described above, dipped in fludioxonil at 300 $\mathrm{mg} / \mathrm{liter}$, and then allowed to air dry. Fruit were placed with the "cheek" side-up in covered plastic containers (31 by 22 by $10 \mathrm{~cm}$ ) (Pioneer Plastics, Dixon, KY) on top of a plastic mesh approximately $1 \mathrm{~cm}$ above the surface of water that was added to the boxes (150 ml per box) to create a high-RH environment. Fruit were either left without wounding or were wounded to a depth of approximately $1 \mathrm{~mm}$ using a 2-mm-diameter sharp-edged glass rod.

Fruit were inoculated by applying $20 \mu \mathrm{l}$ of a suspension of $10^{6}$ conidia/ml to each wounded or nonwounded fruit cheek. Fruit were incubated at $24 \pm 2{ }^{\circ} \mathrm{C}$ for 5 days. Lesion diameters were measured in two perpendicular directions, values were averaged for each lesion, and the area of the circular lesion was calculated.
To investigate the effect of spore concentration on sour rot development, mature nectarine fruit ('Summer Fire') were surface sterilized and prepared for inoculation as described previously. Conidial suspensions of $G$. candidum were adjusted to $10^{3}, 10^{4}$, $10^{5}$, or $10^{6}$ conidia $/ \mathrm{ml}$. There were eight replicates for each inoculum concentration in a randomized complete block design and four fruit were inoculated per replicate. Lesion diameters in two perpendicular directions were measured and recorded as described previously.

Transmission of $\boldsymbol{G}$. candidum inoculum by insects. To determine the role orchard insects play in the sour rot disease, five wounded and five nonwounded peach fruit were enclosed with one fruit inoculated and decayed by G. candidum in an insect cage (71 by 20 by $19 \mathrm{~cm}$ ) covered with plastic mesh (1- $\mathrm{mm}^{2}$ opening). Then, 5 or 10 lab-reared nitidulid beetles (Carpophilus hemipterus) were added to each cage (20). The experiment was performed twice. In the first experiment using 'Elegant Lady' peach, one cage without beetles was used as a control, whereas two or three cages contained 5 or 10 beetles, respectively. In the second experiment, with 'O'Henry' peach, three cages without insects were used as controls and three cages each contained 5 or 10 beetles. Insect cages were kept at $23 \pm 2^{\circ} \mathrm{C}$ for 5 to 6 days before results were recorded as presence or absence of sour rot in the initially healthy fruit. In another experiment, dried fruit beetles and fruit flies $(D$. melanogaster) were collected from fruit dump sites adjacent to a packinghouse and killed by freezing (23). The nitidulid beetles ( $n$ $=101)$ and fruit flies $(n=54)$ were then plated onto PDANF without surface sterilization. Plates were incubated at $23 \pm 2{ }^{\circ} \mathrm{C}$ for 5 days and the number of insects carrying $G$. candidum propagules was recorded. To determine whether the insects carried the propagules within their digestive system, 70 dried fruit beetles and 40 fruit flies were collected from the same fruit dump sites, surface sterilized with $0.61 \% \mathrm{NaOCl}$ for $30 \mathrm{~s}$, and plated as described previously.

Experimental design and analysis. The general experimental design for each test conducted was a completely random design unless specified otherwise. Each experiment was performed at least twice. Readings from the three plates to enumerate $G$. candidum population on leaves and fruit were averaged before data were transformed to $\ln \mathrm{CFU}+1$ for statistical analysis. Correlations between soil, leaf, and fruit surface populations were determined using Spearmen's rank correlation (JMP ver. 8 software; SAS Institute, Cary, NC) after log transformation of the data. Population data from the packinghouses are presented as total numbers of $\mathrm{CFU}$ in each replicate and were analyzed using a Poisson regression with PROC MIXED (SAS ver. 9.1; SAS Institute). Data from the experiments with different inoculum concentrations were analyzed by analysis of variance (ANOVA) using JMP software. In the experiments to test the effect of fruit maturity stage on sour rot susceptibility, data from "immature green" fruit were excluded from the analysis (all such fruit were resistant). Data from the other maturity stages were analyzed by transforming the values to square lesion diameter to meet the $\mathrm{W}$ value at or greater than 0.95 in the Shapiro-Wilk test for normality. Although the Shapiro-Wilk test was significant with a $P=0.002$, indicating that these data were not normally distributed, the data were treated as normally distributed because the $\mathrm{W}$ value calculated was greater than 0.95 and, thus, sufficient to meet the criteria for ANOVA within the parameters of that test. Data were analyzed using repeated measures ANOVA by PROC MIXED. The effect of insects on the incidence

Table 1. Mean CFU of Geotrichum candidum isolated from soil, leaf surface, and fruit surface of peach and nectarine fields in three counties in central California

\begin{tabular}{|c|c|c|c|c|c|c|c|}
\hline Source & Range & Mean & $\begin{array}{l}\text { Number of fields } \\
\text { with } G . \text { candidum }^{\mathrm{z}}\end{array}$ & $\begin{array}{c}\text { Number of fields } \\
\text { sampled over } \\
3 \text { years }\end{array}$ & $\begin{array}{l}\text { Fields with } G . \\
\text { candidum }(\%)\end{array}$ & $\begin{array}{c}\text { Number of } \\
\text { samples positive } \\
\text { with } G \text {. candidum }\end{array}$ & $\begin{array}{l}\text { Number of total } \\
\text { samples sampled } \\
\text { over } 3 \text { years }\end{array}$ \\
\hline Soil & $0-17,111(\mathrm{CFU} / \mathrm{g})$ & $425.9 \pm 151.1$ & 41 & 43 & 95.3 & 67 & 119 \\
\hline Fruit & $0-1,200$ (CFU/fruit) & $23.8 \pm 13.4$ & 15 & 39 & 38.7 & 16 & 100 \\
\hline Leaf & 0-323 (CFU/leaf) & $8.2 \pm 3.7$ & 14 & 43 & 32.6 & 15 & 118 \\
\hline
\end{tabular}

${ }^{\mathrm{z}}$ Number of fields where propagules of G. candidum were detected at least once during 3 years of sampling. 
of sour rot was analyzed by the Wilcoxon or Kruskal-Wallis rank sums tests, while the percentage of insects carrying the fungus was analyzed by a contingency table.

\section{Results}

Sources of inoculum in the field and on harvest equipment. G. candidum was present in the soil $(426 \pm 151 \mathrm{CFU} / \mathrm{g}$ soil) and on leaf $(8 \pm 4 \mathrm{CFU} /$ leaf $)$ and fruit $(24 \pm 13 \mathrm{CFU} /$ fruit) surfaces (Table 1). The propagule density ranged from 0 to $17,111 \mathrm{CFU} / \mathrm{g}$ of soil, 0 to $1,200 \mathrm{CFU} /$ fruit, and 0 to $323 \mathrm{CFU} / \mathrm{leaf}$. G. candidum was detected in the soil in $95 \%$ of the fields sampled, and on the $39 \%$ of the fruit and $37 \%$ of the leaves sampled. Soil population size was significantly correlated with that on leaf $(P=0.0097, \rho=0.2363)$ and fruit $(P=0.007, \rho=0.2669)$ surfaces. However, there was no correlation between populations on leaf and fruit surfaces $(P=$ $0.283, \rho=0.1094)$. Also, no significant correlation was found between organic matter content of orchard soils and the number of propagules (CFU) in soil in $2007\left(y=0.2441 x \pm 0.5669, n=23, R^{2}\right.$ $=0.1347, P>0.05)$ and $2008\left(y=0.0983 x \pm 1.3828, n=20, R^{2}=\right.$ $0.0291, P>0.05)$.

Soil populations of $G$. candidum at varying depths. $G$. candidum propagules were recovered from the three soil depths evaluated (i.e., 2.5, 5, and $10 \mathrm{~cm}$; Table 2). Although, in the third field, a trend was observed for the reduction in the number of propagules with increasing depth to $10 \mathrm{~cm}$ (Table 2), analysis indicated that $G$. candidum populations at different depths were not significantly different $(P=0.35)$. However, there was only a significant difference among orchards sampled $(P=0.002)$. The effect of year sampled and all other possible interactions between soil depth, orchard, and year were not statistically significant.

Sources of inoculum in the packinghouse and ripening room. Spores of G. candidum were detected on all four areas of the packing line in all seven packinghouses (Table 3). Populations were the highest in area 1 of the packing line and decreased significantly in area 2, and then increased significantly in areas 3 and $4(P<$ 0.0001; Tables 4 and 5). The statistical model showed significant differences among packinghouses $(P<0.0001)$. The model showed that there were significant differences between areas sampled among different packinghouses $(P<0.012$; Table 4$)$. For example, in packinghouse 3 , the $G$. candidum population in area 3 was significantly higher than the population in area $2(P=0.025)$ but

Table 2. Populations of Geotrichum candidum propagules at three different depths in soil of three stone fruit fields sampled over 2 years

\begin{tabular}{lrrrr}
\hline & \multicolumn{3}{c}{ Field $^{\mathbf{y}}$} & \\
\cline { 2 - 4 } Depth $(\mathbf{c m})$ & \multicolumn{1}{c}{$\mathbf{1}$} & $\mathbf{2}$ & $\mathbf{3}$ & \multicolumn{1}{c}{ Average $^{\mathbf{z}}$} \\
\hline 2.5 & 91.8 & 364.0 & 61.2 & $91.8 \mathrm{~A}$ \\
5.0 & 100.5 & 360.4 & 46.9 & $119.3 \mathrm{~A}$ \\
10.0 & 44.2 & 477.2 & 2.5 & $41.1 \mathrm{~A}$ \\
\hline
\end{tabular}

y Detransformed data are expressed as least squares mean CFU/g \pm 0.9 .

${ }^{\mathrm{z}}$ Detransformed data are expressed as least squares mean CFU/g \pm 0.7 . Pairwise differences between least square means were converted to letter groupings using the PDMIX800 macro. Least squares means with the same letters are not significantly different. was not significantly higher than the population in area $1(P=$ 0.63; Table 3). However, the populations in all the areas in packinghouse 4 were not significantly different $(P>0.05)$. $G$. candidum spores were not detected in air samples collected in the ripening room using the Andersen trap.

Survival of $\boldsymbol{G}$. candidum in soil at two different depths. There were significant depth $(P<0.0018)$ and time $(P<0.0001)$ effects for spore survival. However, there was a significant interaction between soil depth and time for spore survival at 10 and $20 \mathrm{~cm}$ deep $(P=0.0004)$. In general, the population at $20 \mathrm{~cm}$ was significantly less than the population at $10 \mathrm{~cm}$ until 80 days after inoculum burial, and then again was significantly less on day 199 and 217 after inoculum burial. At $10 \mathrm{~cm}$ deep, spore populations measured 2 weeks after the outset of the experiment had declined to $19.5 \%$ of the original population. After 1 month, the population increased to $137 \%$ of the original population but then declined over the next month to $1.8 \%$ of the initial population. Thereafter, the population increased again to $43.4 \%$ of the initial population. In contrast, at $20 \mathrm{~cm}$ deep, G. candidum population decreased to $52.7 \%$ of the initial population after 2 weeks and decreased further to $0.3 \%$ after 1 month. The population was only $1.5,0.5$, and $1 \%$ during the following sampling points (Fig. 2). At 10- and $20-\mathrm{cm}$ depths, the population remained very low after March and declined to less than $2 \%$ until the last sampling point, 358 days after the placement of inoculum in soil (Fig. 2).

Incidence of sour rot in the field. Only nectarine fruit collected from four fields from a total of six sampled fields developed sour rot. These fruit were harvested directly from the orchard, had not received any postharvest treatment, and were incubated at $20^{\circ} \mathrm{C}$ and $90 \% \mathrm{RH}$. The incidence of decayed fruit was the highest in field 1 ( $3.8 \pm 1.3 \%$; Table 5$)$.

Maturity stages and the effect of wounding and inoculum concentration on disease development. Significantly more sour rot developed on wounded fruit than on unwounded fruit $(P<$ $0.0001)$ and as firmness decreased $(P<0.0001)$ (Fig. 3). For nectarine fruit, there was a significant interaction between maturity stage and wounding $(P=0.03)$. Green immature fruit did not develop any decay, whereas wounded fruit developed significantly larger lesions than unwounded fruit. Furthermore, lesion size increased as firmness decreased. The largest average lesion diameter $(35.3 \pm 0.8 \mathrm{~mm})$ occurred in wounded fruit with 0.9 to $1.4 \mathrm{~kg}$ of firmness (i.e., soft fruit). Unwounded soft fruit developed comparable lesions, with an average diameter of $22.1 \pm 1.4 \mathrm{~mm}$. Wounded fruit at 5.0 to $5.4 \mathrm{~kg}$ of firmness had an average lesion diameter of $21.9 \pm 1.3$. Disease severity decreased significantly as firmness increased in fruit that were not wounded.

Inoculum concentration influenced the size of lesions developing in artificially inoculated nectarine fruit. In one experiment, fruit inoculated with 20 or 200 spores had significantly smaller lesions than fruit inoculated with 2,000 or 20,000 spores $(P=0.0011)$. However, in a second experiment, only fruit inoculated with 20 spores had a significantly smaller lesion diameter than fruit inoculated with the other concentrations $(P<0.0005$; Fig. 4).

Insect transmission. Nitidulid beetles and fruit flies acquired $G$. candidum naturally in the orchard, with $25 \%$ of nitidulid beetles ( $n$ $=101)$ and $26 \%$ of fruit flies $(n=54)$ collected directly from the

Table 3. Population of Geotrichum candidum on packing lines of seven packinghouses at four different areas on the packing line: fruit unloading (area 1), brushes (area 2), after brushes (area 3), and final table (area 4)

\begin{tabular}{|c|c|c|c|c|c|c|c|c|}
\hline \multirow[b]{2}{*}{ Area } & \multicolumn{7}{|c|}{ Packinghouse $^{\mathrm{y}}$} & \multirow[b]{2}{*}{ Average $^{\mathrm{z}}$} \\
\hline & 1 & 2 & 3 & 4 & 5 & 6 & 7 & \\
\hline 1 & 332.6 & 981.4 & $1,479.3$ & 46.5 & 144.5 & 116.9 & 15.44 & $180.3 \mathrm{~A}$ \\
\hline 2 & 3.3 & 48.9 & 110.1 & 45.5 & 2.1 & 5.2 & 0.1 & $10.4 \mathrm{C}$ \\
\hline 3 & 15.1 & 16.0 & $3,009.9$ & 13.6 & 879.1 & 2.1 & 1.8 & $35.6 \mathrm{~B}$ \\
\hline 4 & 16.0 & 171.4 & $1,063.2$ & 17.0 & 1175.2 & 6.6 & 2.5 & $55.3 \mathrm{~B}$ \\
\hline
\end{tabular}

${ }^{y}$ Detransformed data are expressed as least squares mean $\mathrm{CFU} / \mathrm{m}^{2} \pm 1.0$.

${ }^{\mathrm{z}}$ Detransformed data are expressed as least squares mean $\mathrm{CFU} / \mathrm{m}^{2} \pm 0.5$. Pairwise differences between least square means were converted to letter groupings using the PDMIX800 macro. Least squares means with the same letters are not significantly different. 
orchard being positive for $G$. candidum when cultured on PDANF medium. Beetles and flies plated directly on PDANF without surface sterilization developed significantly more $G$. candidum colonies compared with beetles and flies collected from the same area but surface sterilized before plating $\left(P=0.0001, \chi^{2}=14.9\right.$, beetles and $P<0.001, \chi^{2}=11.3$, flies). Only about $3 \%$ of nitidulid beetles $(n=70)$ yielded $G$. candidum colonies after surface sterilization compared with none of the fruit flies $(n=37)$.

In laboratory experiments, nitidulid beetles successfully transmitted G. candidum to wounded and unwounded fruit, with significantly higher disease incidence on wounded fruit (Fig. 5) $\left(\chi^{2}=9.6\right.$, $P=0.002$ ). Increasing the number of insects from 5 to 10 insects per cage did not significantly increase the percentage of fruit infected with sour rot $\left(\chi^{2}=3.07, P=0.08\right)$.

\section{Discussion}

G. candidum has been reported to be found in the soil (9). Also, the two mating types that describe the sexual stage of $G$. candidum were first isolated from soils from Puerto Rico $(10,11)$. In the present study, G. candidum was found in soil from California peach and nectarine orchards, with recovery of the pathogen more frequent from soil than from fruit and leaf surfaces. G. candidum was detected in $95 \%$ of the orchards sampled but only in 67 of the 119 soil samples collected, suggesting high variation in the density of propagules in the soil.

Results from surveys of stone fruit orchards agree with a survey of G. citri-aurantii, the causal agent of sour rot on citrus, where G. citri-aurantii was detected in 62 to $95 \%$ of the samples collected $(14,28)$. The citrus strain also was isolated from fruit surfaces (4). The correlation between the soil population and the population on leaf and fruit surfaces suggests that orchards with high soil populations are at higher risk to develop sour rot if other factors are equally favorable for disease development. Although environmental conditions favorable for sour rot occur infrequently in California orchards, the disease occasionally is observed in the field, especially in orchards where irrigation practices and site characteristics lead to episodes of high

Table 4. Analysis of variance for mixed model of data on propagules of Geotrichum candidum recovered from packing lines in packinghouses of stone fruit

\begin{tabular}{lrrc}
\hline Effect & df & $\boldsymbol{F}$ & $\boldsymbol{P}>\boldsymbol{F}^{\mathbf{z}}$ \\
\hline Year & 1 & 4.34 & $0.038^{*}$ \\
Packinghouse & 6 & 12.68 & $<0.0001^{*}$ \\
Year $\times$ packinghouse & 6 & 2.67 & $0.015^{*}$ \\
Stage & 3 & 9.29 & $<0.0001^{*}$ \\
Year $\times$ stage & 3 & 0.73 & 0.537 \\
Packinghouse $\times$ stage & 18 & 1.96 & $0.012^{*}$ \\
Year $\times$ packinghouse $\times$ stage & 18 & 1.26 & 0.214 \\
Sampling time (year) & 12 & 1.63 & 0.083 \\
Sampling time $\times$ stage (year) & 36 & 0.88 & 0.666 \\
\hline
\end{tabular}

${ }^{\mathrm{z}}$ Asterisk (*) indicates significance. Data were analyzed as repeated measures using PROC MIXED. Sampling time was nested within year and interaction between year and stage was nested within year.

Table 5. Descriptive statistics of percentages of fruit with sour rot harvested directly from stone fruit orchards and placed in commercial packing boxes ${ }^{y}$

\begin{tabular}{lccc}
\hline Field & Range & Mean & Standard error \\
\hline $1^{\mathrm{z}}$ & $0-20.8$ & 3.8 & 1.3 \\
2 & $0-4.2$ & 1.3 & 0.4 \\
3 & $0-2.1$ & 0.1 & 0.1 \\
4 & ND & ND & ND \\
5 & ND & ND & ND \\
6 & $0-4.1$ & 0.3 & 0.2 \\
\hline
\end{tabular}

${ }^{y}$ Forty-eight fruit per box and 10 boxes were incubated at $20^{\circ} \mathrm{C}$ and $90 \%$ relative humidity for 5 days $(n=20)$. ND = sour rot was not detected in the field during a 2-year sampling period.

${ }^{\mathrm{z}} n=17$. humidity or where many fallen fruit are allowed to remain on the ground.

Contaminated soil and debris as well as propagules on leaves and fruit surfaces can be transported from the orchard to the packinghouse to contaminate the packing line. Subsequently, a contaminated packing line can serve as a source of inoculum to infect healthy fruit. Previous studies have shown that orchard soil adhering to harvest bins can be a source of inoculum in packinghouses for other postharvest diseases $(18,22)$. Soil and organic debris also can contaminate hydrocooling water, thus reducing the efficacy of chlorinated water as a primary disinfectant in the early stages of the fruit packing process $(27,31)$.

All soil samples used to enumerate $G$. candidum populations were collected from no-till orchards. Leaf litter, chipped wood from pruned branches, and pits of fallen fruit accumulate on these orchard floors. In contrast to other findings on the relationship of organic matter to fungal biomass, we did not find a significant correlation between soil organic matter and G. candidum population levels. Plant debris on the orchard floor may increase soil organic matter, as previous studies have shown (15). The addition of wheat straw on the surface of no-till soils as an organic amendment

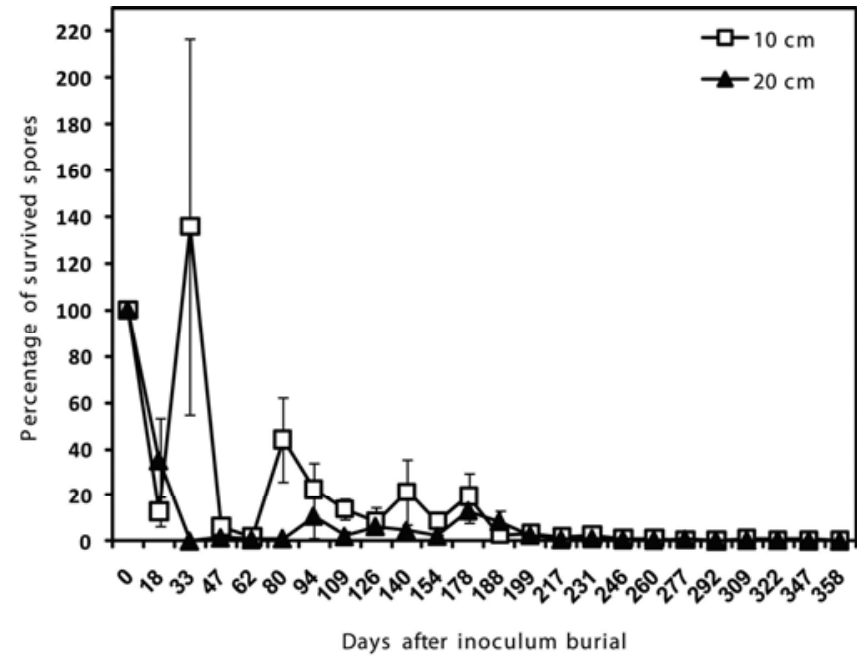

Fig. 2. Survival of Geotrichum candidum propagules at $10(\square)$ and $20(\mathbf{\Lambda}) \mathrm{cm}$ deep in orchard soil at Kearney Agriculture Center, Parlier, CA. Experiment started on 28 August 2008 and ended on 21 August 2009. Thirty decayed fruit were blended and mixed with $25 \mathrm{~kg}$ of soil and placed in 12 wire baskets and buried in the soil. Bars indicate standard errors.

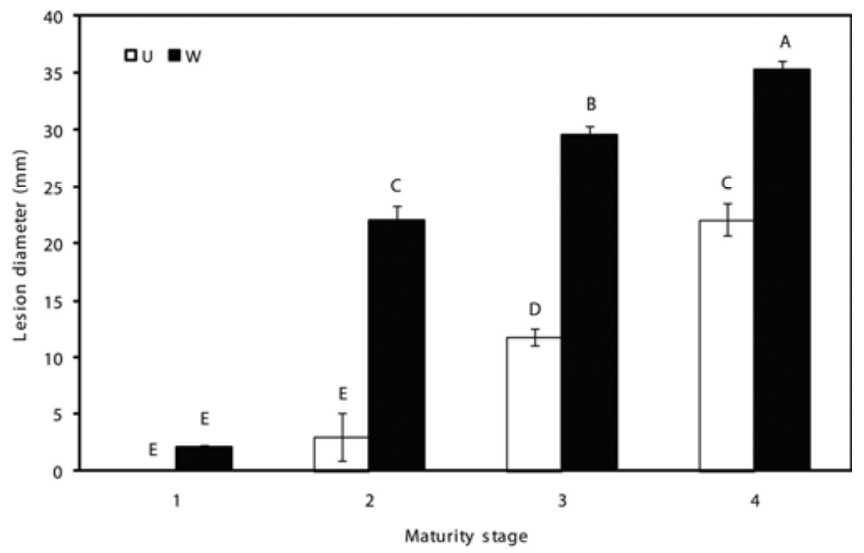

Fig. 3. Sour rot development on wounded (W) and unwounded (U) nectarine ('May Glo') with four maturity stages: green immature (stage 1), 5.0 to $5.4 \mathrm{~kg}$ of resistance (stage 2), 2.7 to $3.6 \mathrm{~kg}$ of resistance (stage 3), and 0.9 to $1.4 \mathrm{~kg}$ of resistance (stage 4). Fruit were incubated at $23.9 \pm 2{ }^{\circ} \mathrm{C}$ and approximately $99 \%$ relative humidity for 5 days and lesion diameters were measured $(n=16)$. Bars indicate standard errors. Letters indicate significant differences at $\alpha=0.05$ using the TukeyKramer test for mean separation. 
has been shown to reduce organic matter losses and increase fungal biomass and activity $(15,26)$. However, this may not necessarily increase the population of plant pathogens living saprophytically on organic matter because microbial antagonists influence the survival of soilborne plant pathogens (3). G. candidum propagules were recovered as deep as $10 \mathrm{~cm}$ (Table 2), and G. candidum populations at the different depths included in this study were not significantly different. However, there was a significant difference among the orchards sampled. The importance of this difference in relation to disease incidence is unclear, because this observation was not further investigated in the present study. Additional research will be needed to assess the epidemiological impact of orchard differences in survival of soilborne inoculum of $G$. candidum on sour rot incidence.

Nitidulid beetles (Carpophilus spp.) successfully transmitted $G$. candidum spores from decayed fruit with sour rot to wounded and nonwounded healthy fruit in laboratory experiments, and wounds significantly increased sour rot incidence due to insect transmission. Fruit flies and nitidulid beetles appear to carry G. candidum spores mainly on their body surface, because no evidence was found for the presence of infective propagules internally. In stone fruit orchards, nitidulid beetles can cause injury primarily to ripe fruit (17). Thus, in peach and nectarine orchards in California, insect visitation of diseased fruit on trees or on the orchard floor provides a pathway for transmission of sour rot disease to healthy, ripe fruit. Although vinegar flies and nitidulid beetles have been reported to vector $G$. candidum and other fungal diseases to various crops $(7,8,23,29)$, the present study is the first report of these insects vectoring $G$. candidum to cause sour rot of peach and nectarine.

Fruit maturity is also an important factor in sour rot disease development. G. candidum can infect firm (immature) fruit if there is a wound but will grow slowly in these fruit until the fruit ripen. Disease development is very rapid in soft (mature) fruit. Because
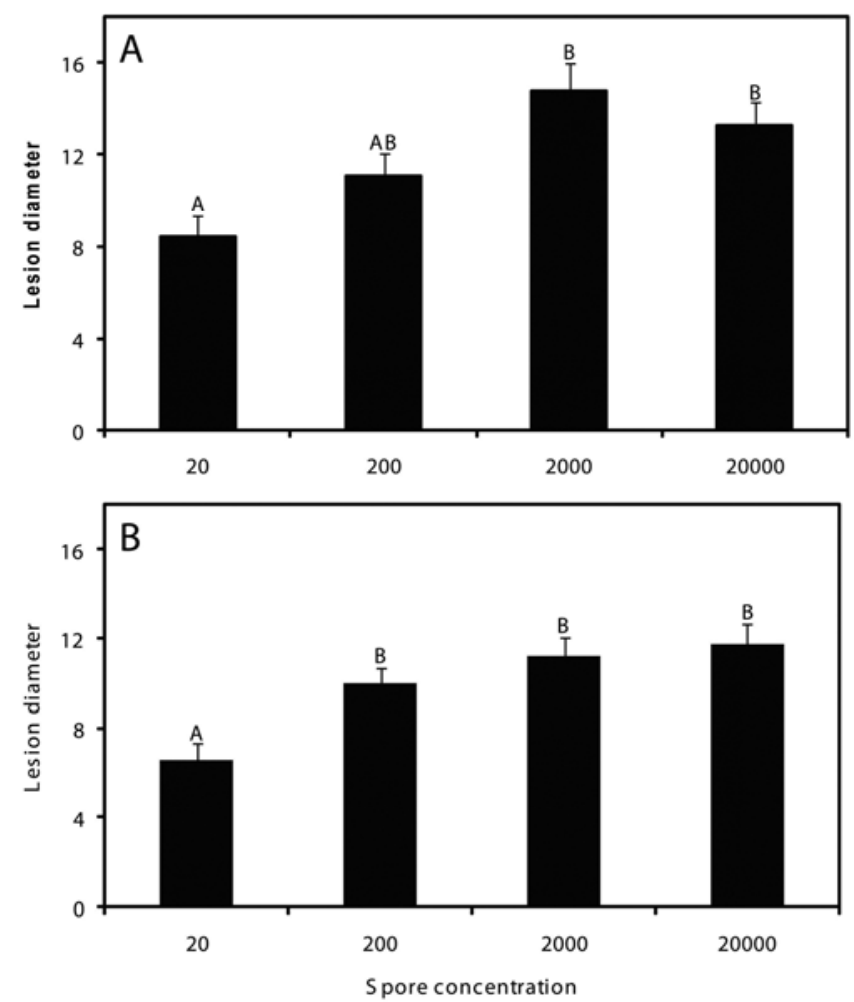

Fig. 4. Development of sour rot on nectarine ('Summer Fire') fruit inoculated with 20 $\mu \mathrm{l}$ of a suspension containing Geotrichum candidum at $10^{3}, 10^{4}, 10^{5}$, or $10^{6}$ spores/ml. A, Experiment 1 and B, Experiment 2. Fruit were incubated at $23.9 \pm$ $2^{\circ} \mathrm{C}$ and approximately $99 \%$ relative humidity for 5 days and lesion diameters were measured. Bars indicate standard errors. Letters indicate significant differences at $\alpha=0.05$ using the Tukey-Kramer test for mean separation. some fruit are infected when firmness is 5.0 to $5.4 \mathrm{~kg}$ of resistance, some decay could develop even before the fruit is preconditioned, assuming that wounds are present and conditions in the orchard are favorable for the development of the pathogen. The softening of the fruit following preconditioning will accelerate the appearance of sour rot symptoms. Similar to our findings, wounds in peach and nectarine markedly increase disease severity and incidence of brown rot caused by $M$. fructicola $(16,32)$.

In a preliminary study conducted in 2006, G. candidum propagules were detected most frequently at areas 2 and 3 of the packing line (data not shown). In a rigorous, replicated study conducted in 2007 and 2008, G. candidum propagules were detected at all four areas in each of the packing lines at seven packinghouses (Table 3). Following our initial report in 2006 concerning contamination of the packing lines, some packinghouses started to clean the brushes more often. Good sanitation practices can significantly reduce spore populations along the packing line. The presence of propagules on the brushes suggests that brushes can "inoculate" fruit during the packing process. Wells (31) found that packinghouses that used poor sanitation had a higher percentage of fruit with sour rot than packinghouses that used good sanitation practices.

Packinghouses in California practice delayed cooling and use reduced-risk fungicides such as fludioxonil. Fludioxonil is very effective against $B$. cinerea and $M$. fructicola. G. candidum probably is more prevalent as a postharvest problem due to delayed cooling at optimum storage temperatures and the use of fungicides such as fludioxonil that select against competing decay fungi such as $B$. cinerea and M. fructicola. Wells (31) also reported that fruit treated with 2,6-dichloro-4-nitroaniline and benomyl had more sour rot than unwaxed fruit. This was due to the selective action of the fungicides against competing decay-causing organisms such as $R$. stolonifer and M. fructicola.

The G. candidum population declined with increasing soil depth, indicating that burying of culled fruit to a depth of $20 \mathrm{~cm}$ will significantly reduce their impact as a source of inoculum in the orchard. Studies have demonstrated that spore survival of other plant pathogens decline with increasing soil depth $(21,25)$. Michailides and Ogawa (21) demonstrated that survival of propagules of Mucor piriformis declined over the course of a year after burying infested soil at 5 and $10 \mathrm{~cm}$ in a Hanford fine sandy loam in a manner similar to the experiment reported in this article. The results of the present study agree with their conclusion that survival of spores from decaying fruit on the orchard floor is minimal if those fruit are crushed, mixed with soil, and buried. This cultural practice can be readily incorporated in sour rot management. Tillage to bury and destroy plant residues is a common method to control soilborne pathogens ( 3 )

The present study revealed that the main source of inoculum is the soil in stone fruit orchards. Spores reach the canopy and land

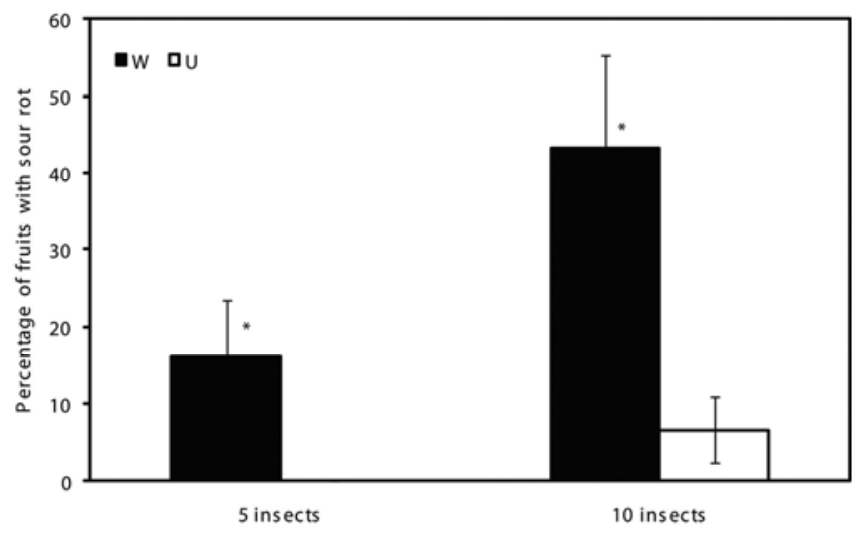

Fig. 5. Incidence of wounded or unwounded fruit decayed by Geotrichum candidum after being caged with 5 or 10 nitidulid beetles (Carpophilus hemipterus) for 5 days. Bars indicate standard errors. Asterisk indicate significant differences at $\alpha=0.05$. 
on leaf and fruit surfaces. If fruit are wounded due to physical or insect damage, then the disease may start in the field. G. candidum spores can contaminate the packing line at the packinghouse through infested soil, contaminated dust on fruit and leaves, and decaying fruit. Disease may develop through infection of microwounds with as little as 20 spores in fruit that have been preconditioned to stimulate ripening.

Disease management in the field and the packinghouse should include effective sanitation practices to reduce sources of inoculum. Also, fruit should be handled with care to minimize injuries. Spore survival experiments in the field indicated that burying cull fruit to depths between 10 and $20 \mathrm{~cm}$ may markedly reduce spore viability, and can be used to manage the disease risk posed by "culled" fruit. Sanitation is a critical component of an integrated strategy for controlling sour rot of peach and nectarine.

\section{Acknowledgments}

We thank J. E. Adaskaveg for his initial review of the manuscript; N. Willits for advice on statistical analyses; G. Browne for making his spiral plater available for our use during this study; and R. Puckett and H. Reyes for their help in sampling.

\section{Literature Cited}

1. Adaskaveg, J. E., and Crisosto, C. H. 2006. Sour rot control. Central Valley Postharvest Newsl. 15:2-5.

2. Adaskaveg, J. E., Förster, H., Driever, G., and Crisosto, C. H. 2006. Scholar's Mentor gets an emergency registration to help manage sour rot of stone fruit in California. Central Valley Postharvest Newsl. 15:2-5.

3. Bockus, W. W., and Shroyer, J. P. 1998. The impact of reduced tillage on soilborne plant pathogens. Annu. Rev. Phytopathol. 36:485-500.

4. Brown, G. E. 1979. Biology and control of Geotrichum candidum, the cause of citrus sour rot. Proc. Fla. State Hortic. Soc. 92:186-189.

5. Burton, C. L., and Wright, W. R. 1969. Sour rot of peaches on the market. Plant Dis. Rep. 53:580-582.

6. Butler, E. E. 1960. Pathogenicity and taxonomy of Geotrichum candidum. Phytopathology 50:665-672.

7. Butler, E. E. 1961. Transmission of Geotrichum rot of tomato fruit by Drosophila melanogaster. Phytopathology 51:250-255.

8. Butler, E. E., and Bracker, C. E. 1963. Role of Drosophila melanogaster in epiphytology of Geotrichum, Rhizopus, and other fruit rots of tomato. Phytopathology 53:1016-1020.

9. Butler, E. E., and Eckert, J. W. 1962. A sensitive method for isolation of Geotrichum candidum from soil Mycologia 54:106-109.

10. Butler, E. E., and Petersen, L. J. 1970. Sexual reproduction in Geotrichum candidum. Science 169:481-482.

11. Butler, E. E., and Petersen, L. J. 1972. Endomyces geotrichum a perfect state of Geotrichum candidum. Mycologia 64:365-374.

12. Crisosto, C. H., Garner, D., Andris, H. L., and Day, K. R. 2004. Controlled delayed cooling extends peach market life. HortTechnology 14:99-104.

13. Eckert, J. W., and Ogawa, J. M. 1988. The chemical control of postharvest diseases: deciduous fruits, berries, vegetables and root tuber crops. Annu. Rev. Phytopathol. 26:433-469.

14. Hershenhorn, J., Dori, S., and Barash, I. 1992. Association of Geotrichum citri-aurantii with citrus groves in Israel. Phytoparasitica 20:31-36.

15. Holland, E. A., and Coleman, D. C. 1987. Litter placement effects on microbial and organic matter dynamics in an agroecosystem. Ecology 68:425-433.

16. Hong, C. X., Michailides, T. J., and Holtz, B. A. 1998. Effects of wounding, inoculum density, and biological control agents on postharvest brown rot of stone fruits. Plant Dis. 82:1210-1216.

17. James, D. G., Faulder, R. J., Vogele, B., and Moore, C. J. 2000. Pheromonetrapping of Carpophilus spp. (Coleoptera : Nitidulidae) in stone fruit orchards near Gosford, New South Wales: fauna, seasonality and effect of insecticides. Aust. J. Entomol. 39:310-315.

18. Lennox, C. L., Spotts, R. A., and Cervantes, L. A. 2003. Populations of Botrytis cinerea and Penicillium spp. on pear fruit, and in orchards and packinghouses, and their relationship to postharvest decay. Plant Dis. 87:639-644.

19. Michailides, T. J., Morgan, D. P., and Day, K. R. 2004. First report of sour rot of California peaches and nectarines caused by yeasts. Plant Dis. $88: 222$.

20. Michailides, T. J., Morgan, D. P., Spotts, R. A., Beglinger, C., and Odiet, P. A. 1992. Role of nititulid beetles and vinegar flies in the sexual cycle of Mucor piriformis in tree fruit orchards. Mycologia 84:488-496.

21. Michailides, T. J., and Ogawa, J. M. 1987. Effect of soil temperature and moisture on the survival of Mucor piriformis. Phytopathology 77:251-256.

22. Michailides, T. J., and Spotts, R. A. 1986. Factors affecting dispersal of Mucor piriformis in pear orchard sand into the packinghouse. Plant Dis. 70:1060-1063.

23. Michailides, T. J., and Spotts, R. A. 1990. Transmission of Mucor piriformis to fruit of Prunus persica by Carpophilus spp. and Drosophila melanogaster. Plant Dis. 74:287-291.

24. Nelson, D. W., and Sommers, L. E. 1996. Total carbon, organic carbon, and organic matter. Pages 1001-1006 in: Methods of Soil Analysis. Part 3 Chemical Methods. SSSA Book Series no. 5. J. M. B. et. al. eds. SSSA, ASA, Madison, WI.

25. Pryor, B. M., Strandberg, J. O., Davis, R. M., Nunez, J. J., and Gilbertson, R. L. 2002. Survival and persistence of Alternaria dauci in carrot cropping systems. Plant Dis. 86:1115-1122.

26. Schnurer, J., Clarholm, M., and Rosswall, T. 1985. Microbial biomass and activity in an agricultural soil with different organic matter contents. Soil Biol. Biochem. 17:611-618.

27. Smilanick, J. L., Aiyabei, J., Gabler, F. M., Doctor, J., Sorenson, D., and Mackey, B. 2002. Quantification of the toxicity of aqueous chlorine to spores of Penicillium digitatum and Geotrichum citri-aurantii. Plant Dis. 86:509-514.

28. Suprapta, D. N., Arai, K., and Iwai, H. 1995. Distribution of Geotrichum candidum citrus race in citrus groves and non-citrus fields in Japan. Mycoscience 36:277-282.

29. Tate, K. G., and Ogawa, J. M. 1975. Nitidulid beetles as vectors of Monilinia fructicola in California stone fruits. Phytopathology 65:977-983.

30. Wade, N. L., and Morris, S. C. 1982. Causes and control of cantaloupe postharvest wastage in Australia. Plant Dis. 66:549-552.

31. Wells, J. M. 1977. Sour rot of peaches caused by Monilinia implicata and Geotrichum candidum. Phytopathology 67:404-408.

32. Xu, X. M., Bertone, C., and Berrie, A. 2007. Effects of wounding, fruit age and wetness duration on the development of cherry brown rot in the UK. Plant Pathol. 56:114-119. 